\title{
Influence of Diabetes Mellitus on Surgical Outcomes in Patients with Cervical Myelopathy: A Prospective, Multicenter Study
}

\author{
Shinji Tanishima ${ }^{1}$, Tokumitsu Mihara $^{1}$, Atsushi Tanida ${ }^{1}$, Chikako Takeda ${ }^{1}$, Masaaki Murata ${ }^{2}$, \\ Toshiaki Takahashi ${ }^{3}$, Koji Yamane ${ }^{3}$, Tsugutake Morishita ${ }^{4}$, Yasuo Morio ${ }^{5}$, Hiroyuki Ishii ${ }^{5}$, Satoru Fukata ${ }^{5}$, \\ Yoshiro Nanjo ${ }^{6}$, Yuki Hamamoto ${ }^{7}$, Toshiyuki Dokai ${ }^{8}$, Hideki Nagashima ${ }^{1}$ \\ ${ }^{1}$ Department of Orthopedic Surgery, Faculty of Medicine, Tottori University, Tottori, Japan \\ ${ }^{2}$ Department of Orthopaedic Surgery, Tottori Central Prefectural Hospital, Tottori, Japan \\ ${ }^{3}$ Department of Orthopedic Surgery, Tottori Red Cross Hospital, Tottori, Japan \\ ${ }^{4}$ Department of Orthopedic Surgery, Tottori Municipal Hospital, Tottori, Japan \\ ${ }^{5}$ Department of Orthopedic Surgery, Misasa Onsen Hospital, Tottori, Japan \\ ${ }^{6}$ Department of Orthopedic Surgery, Sanin Rosai Hospital, Yonago, Japan \\ ${ }^{7}$ Department of Orthopaedic Surgery, Matsue City Hospital, Matsue, Japan \\ ${ }^{8}$ Department of Orthopedic Surgery, Masuda Red Cross Hospital, Masuda, Japan
}

Study Design: Multicenter, prospective study.

Purpose: To investigate the effects of diabetes mellitus (DM) on surgical outcomes in patients with cervical myelopathy.

Overview of Literature: To date, few studies have investigated the influence of postoperative blood glucose or glycated hemoglobin (HbA1c) levels on surgical outcomes.

Methods: The participants were patients who underwent surgery for the treatment of cervical spondylotic myelopathy and ossification of the posterior longitudinal ligament. The 61 cases were evaluated preoperatively and 1 year postoperatively using the Japanese Orthopaedic Association (JOA) scores and the JOA Cervical Myelopathy Evaluation Questionnaire (JOACMEO). The study variables included fasting blood glucose and HbA1c levels measured preoperatively and at 1 week, 4 weeks, and 1 year postoperatively; the F-wave conduction velocity, latency, rate of occurrence, and M-wave latency in the ulnar and tibial nerves were measured preoperatively and at 1 year postoperatively. The patients were divided into a group without diabetes ( $\mathrm{N}$ group, 42 patients) and a group with diabetes (DM group, 19 patients). We then assessed the associations between the surgical outcomes and each of the study variables. Results: JOA scores significantly improved in both groups; however, no significant between-group differences were found. There was no significant improvement in the JOACMEO scores, which assessed cervical function, upper and lower limb function, and bladder function in both groups. We then subdivided the DM group into those with a good control of HbA1c after 1 year (DMG group, 12 patients) and those with HbA1c deterioration after 1 year (DMB group, seven patients), prior to comparing the surgical outcomes. The JOACMEQ scores for upper and lower limb function significantly improved in the DMG group $(p<0.01)$. Compared with the DMB group, there were no significant increases in upper or lower limb function scores in the DMG group.

Conclusions: Poor glycemic control might prevent postoperative functional recovery of the spinal cord.

Keywords: Neck; Spinal cord compression; Diabetes mellitus; Treatment outcome; Electromyography

Received Apr 19, 2018; Revised Jul 12, 2018; Accepted Jul 25, 2018

Corresponding author: Shinji Tanishima

Department of Orthopedic Surgery, Faculty of Medicine, Tottori University, 36-1 Nishi-cho, Yonago, Tottori 683-8504, Japan

Tel: +81-859-38-6587, Fax: +81-859-38-6589, E-mail: shinji@sanmedia.or.jp 


\section{Introduction}

Cervical spondylotic myelopathy (CSM) is generally observed in adults aged $>50$ years $[1,2]$. Common symptoms include numbness in the upper extremities (UE) and lower extremities (LE), bilateral impairments in dexterity, spastic gait disturbances, and bladder and bowel dysfunction. Treatment for CSM is well established; however, there are several risk factors for poor surgical outcomes. A previous study reported that the prevalence of diabetes mellitus (DM), hypertension, hyperlipidemia, and the use of anticoagulant and/or antiplatelet agents could affect cervical laminoplasty outcomes [3]. Associations between DM and surgical outcomes in patients with CSM have been reported in several recent publications [3-6].

Dokai et al. [5] has reported that patients with DM and CSM exhibited a poorer recovery of sensory function in the LE and an overall poorer recovery ratio (RR). Furthermore, Nakanishi has proposed that disruptions in microvascular structures that result from DM influence CSM outcomes [7].

DM is a frequent comorbidity that affects many organs and causes numbness and weakness in the extremities due to peripheral nerve damage. The effects of DM on the peripheral nervous system and microvasculature are of concern.

Surgeons must consider issues surrounding DM control during the perioperative period. Previous reports have indicated that preoperative glycated hemoglobin ( $\mathrm{HbAlc}$ ) and blood sugar levels affect surgical outcomes in patients with CSM. However, few studies have examined the influence of postoperative blood glucose or HbAlc levels on surgical outcomes. Our study investigated the effects of DM on surgical outcomes in patients with CSM by assessing DM control postoperatively.

\section{Materials and Methods}

We performed a prospective multicenter study at Tottori University Hospital, comprising eight hospitals in and around the Tottori Prefecture in Japan from 2012 to 2015.

Informed consent was obtained from all participants. Inclusion criteria were patients who underwent surgical treatments for CSM and ossification of the posterior longitudinal ligament. We used magnetic resonance imaging (MRI) to determine the compression level and regarded the compression level with cord intensity change at T2WI.
If cord intensity changes were never determined, we considered the level of most severe stenosis within the cervical spine as the origin of the myelopathy.

All the patients underwent laminoplasty or anterior decompression and fusion at the discretion of the spinal surgeon at each institution. Exclusion criteria were (1) past history of cervical spine surgery; (2) congenital deformity of the cervical spine; (3) infection; (4) trauma; (5) tumor; (6) rheumatoid arthritis; (7) cervical palsy; (8) pacemaker treatment; and (9) paralysis without cervical disorder. The patients were divided into two groups: a group without diabetes ( $\mathrm{N}$ group) and a group with diabetes (DM group). $\mathrm{DM}$ was diagnosed if any or all the following criteria were met, as defined by the Japan Diabetes Society: (1) fasting blood sugar $>126 \mathrm{mg} / \mathrm{dL}$, (2) causal blood sugar over 200 $\mathrm{mg} / \mathrm{dL}$; (3) blood sugar over $200 \mathrm{mg} / \mathrm{dL}$ under 2 hours $75 \mathrm{~g}$, and oral glucose-tolerance test; and (4) HbAlc over 6.5\%.

The patients diagnosed with diabetic mellitus were treated with intensive blood sugar control by a doctor of internal medicine during the perioperative period. This study was approved by the local ethics committee of the Faculty of Medicine, Tottori University (IRB approval no., 1824).

\section{Surgical outcomes}

The Japanese Orthopaedic Association (JOA) [8] and the Japanese Orthopaedic Association Cervical Myelopathy Evaluation Questionnaire (JOACMEQ) [9] scores were obtained to measure surgical outcomes preoperatively and at 1 year postoperatively. We calculated the RR as follows [10]: RR (\%)=(postoperative JOA score-preoperative JOA score) $/\{17$ (fullmark)-preoperative JOA score $\} \times 100$.

\section{Patient characteristics}

Patient characteristics recorded included sex, age, height, weight, body mass index, and disease duration.

\section{Diabetes mellitus}

We evaluated fasting blood glucose (FBG) and HbAlc levels via routine blood testing preoperatively and 1 week, 4 weeks, and 1 year postoperatively.

\section{Electrophysiological evaluation}

$\mathrm{M}$ - and F-waves were recorded from the ulnar and tibial 
nerves. Surface recording electrodes were placed bilaterally on the abductor digiti minimi and abductor hallucis muscles. Stimulations were delivered from the proximal elbow to the ulnar nerve and from the popliteus to the tibial nerve. The peripheral conduction time (PCT) was calculated using Kimura's method [11]. The PCT, excluding the turnaround time at the spinal motor neuron (1 $\mathrm{ms}$ ), was calculated from the compound muscle action potential and F-waves as follows: (M-wave latency+Fwave latency-1)/2.

These assessments were performed preoperatively and 1 year postoperatively.

\section{Statistical analysis}

All the data are expressed as mean \pm standard deviation. The statistical analyses were performed using StatMate ver. 5.0 for Windows and Mac (ATMS Co., Tokyo, Japan). Differences between groups were determined using Pear- son's chi-square test, Fisher's exact test, and the MannWhitney $U$-test. We performed Fisher's exact test when the expected cell size was $<5$. The Mann-Whitney $U$-test was used for comparing JOA scores between groups. We compared PCT data between the two groups using Welch's $t$-test.

Between-group differences in FBG and HbA1c levels were compared using paired $t$-tests. Correlations between the RR of the JOA score and FBG and HbAlc levels were estimated using the Pearson correlation coefficient (r). The Mann-Whitney $U$-test was used to compare JOA scores between the groups. After excluding patients whose pretreatment and post-treatment scores were $\geq 90$ points from the analysis according to a previous report on the JOABPEQ [9], the Wilcoxon signed-rank test was used to determine categorical changes within the JOACMEQ scores in each group. The results were considered to be significant when $p<0.05$.

Table 1. Patient characteristics and demographics

\begin{tabular}{|c|c|c|c|}
\hline Characteristic & $\mathrm{N}$ group & DM group & $p$-value \\
\hline Age (yr) & $69.6 \pm 13.3$ & $69.3 \pm 10.7$ & $0.78^{\text {a) }}$ \\
\hline Gender (male:female) & $25: 11$ & $12: 17$ & $0.79^{b)}$ \\
\hline Height (cm) & $158.5 \pm 9.6$ & $160.7 \pm 10.2$ & 0.43 \\
\hline Weight (kg) & $57.6 \pm 12.2$ & $60.1 \pm 11.7$ & 0.28 \\
\hline Body mass index $\left(\mathrm{kg} / \mathrm{m}^{2}\right)$ & $22.8 \pm 3.4$ & $23.2 \pm 3.7$ & $0.72^{\text {a) }}$ \\
\hline CSM:OPLL & $29: 13$ & $14: 5$ & $0.71^{\mathrm{bl}}$ \\
\hline \multicolumn{4}{|c|}{ Peripheral conduction time (ms) } \\
\hline Ulna (right) & $15.3 \pm 2.3$ & $17.4 \pm 6.2$ & $0.05^{\mathrm{a})}$ \\
\hline Ulna (left) & $15.5 \pm 2.7$ & $17.3 \pm 5.2$ & $0.08^{\mathrm{a})}$ \\
\hline Tibia (right) & $25.6 \pm 2.9$ & $27.1 \pm 3.0$ & $0.09^{\mathrm{a})}$ \\
\hline Tibia (left) & $25.6 \pm 3.1$ & $26.8 \pm 3.0$ & $0.14^{\mathrm{a})}$ \\
\hline JOA score (total) & $10.9 \pm 2.8$ & $10.8 \pm 7.5$ & $0.80^{\text {a) }}$ \\
\hline \multicolumn{4}{|l|}{ JOACMEO } \\
\hline Cervical & $70.5 \pm 30.7$ & $62.6 \pm 30.2$ & 0.37 \\
\hline Upper extremity & $66.7 \pm 23.7$ & $72.4 \pm 18.2$ & 0.47 \\
\hline Lower extremity & $52.3 \pm 31.7$ & $52.3 \pm 26.4$ & 0.91 \\
\hline Bowe \& bladder & $68.9 \pm 19.2$ & $71.7 \pm 16.1$ & 0.98 \\
\hline Quality of life & $45.3 \pm 16.0$ & $38.6 \pm 18.9$ & 0.15 \\
\hline
\end{tabular}

Values are presented as mean \pm standard deviation or number. No variables significantly differed between the groups (a group without diabetes [N group] and a group with diabetes [DM group]).

DM, diabetes mellitus; CSM, cervical spondylotic myelopathy; OPLL, ossification of the posterior longitudinal ligament; JOA, Japanese Orthopaedic Association; JOACME0, JOA Cervical Myelopathy Evaluation Questionnaire.

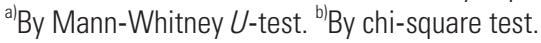




\section{Results}

\section{Patients}

A total of 148 participants were registered. A total of 140 patients were included during the 3-year study period. Seventy-nine of these patients were excluded: 66 for missing values at the 1-year follow-up, two patients died, two patients suffered from lumbar spinal stenosis, two patients had spinal injuries, one patient had cerebrovascular disease, one patient was diagnosed with bile duct cancer, one patient was diagnosed with a vitamin B12 deficiency postoperatively, and four patients failed to present for the 1 -year follow-up appointment, resulting in 61 evaluable patients. The patients were then divided into two groups: a group without diabetes ( $\mathrm{N}$ group, 42 patients) and a group with diabetes (DM group, 19 patients). The characteristics of the $\mathrm{N}$ and DM groups are presented in Table 1. There were no significant between-group differences.

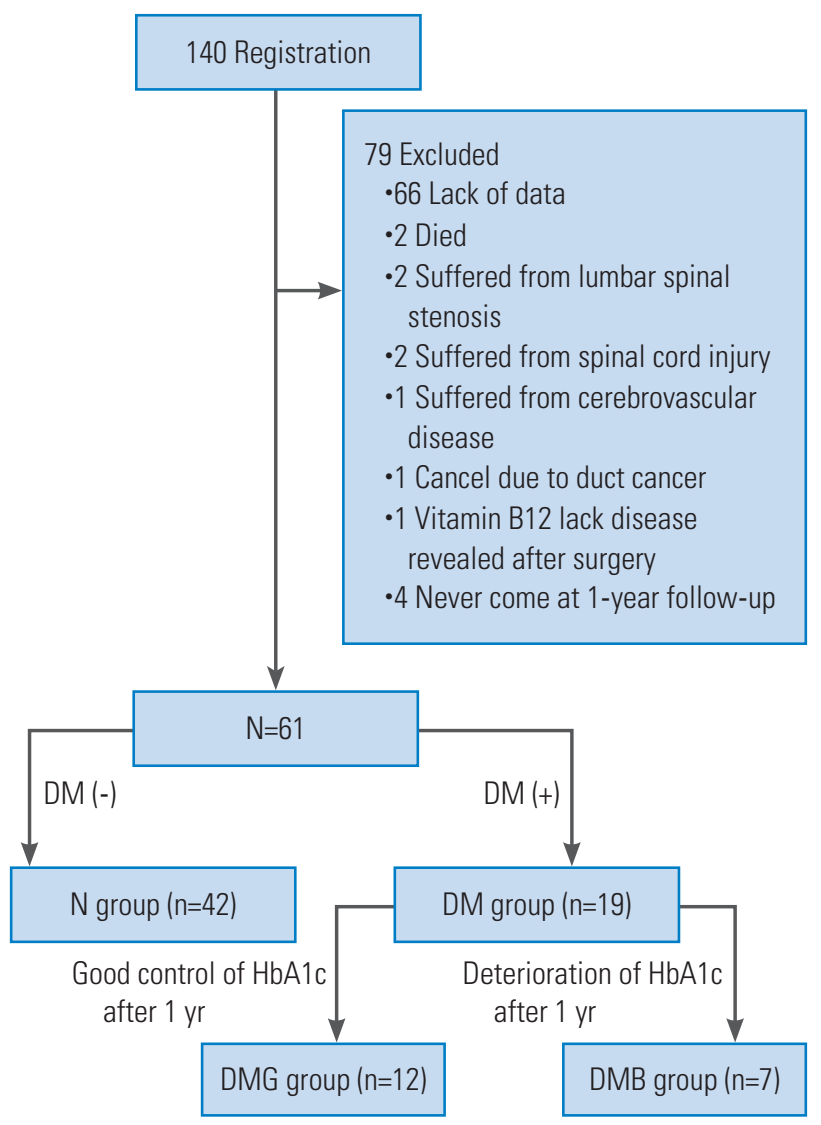

Fig. 1. Study flowchart. N group: a group without diabetes; DM group: a group with diabetes; DMG group: those with a good control of $\mathrm{HbA1c}$ after 1 year; DMB group: those with $\mathrm{HbA1c}$ deterioration after 1 year. DM, diabetes mellitus; HbA1c, glycated hemoglobin.
We also divided the DM group into two subgroups according to $\mathrm{HbA} 1 \mathrm{c}$ levels over the preoperative period and the levels at the 1-year follow-up, in order to investigate the effects of HbA1c levels on surgical outcomes. The DMG group $(n=12)$ consisted of individuals with good DM control at the 1-year follow-up. The DMB group $(n=7)$ consisted of patients with DM control deteriorations at the 1-year follow-up (Fig. 1).

\section{Diabetes mellitus control from the preoperative pe- riod until the 1-year follow-up}

FBG and HbA1c level changes are shown in Table 2. In the $\mathrm{N}$ group, FBG levels significantly decreased at 1 week compared with the preoperative value. FBG levels at postoperative week 4 and at 1 year did not significantly change relative to the preoperative values. HbAlc levels did not significantly change between the preoperative and postoperative visits. Although FBG levels significantly improved at 1 and 4 weeks postoperatively, FBG levels at 1 year postoperatively were not significantly different from the preoperative values. The HbAlc levels were significantly decreased only at 4 weeks postoperatively.

\section{Surgical outcomes based on the Japanese Orthopaedic Association scores}

JOA scores significantly improved in both groups postoperatively ( $\mathrm{N}$ group, $p<0.01$ and $\mathrm{DM}$ group, $p=0.01$ ). The $\mathrm{RR}$ was 40.1 in the $\mathrm{N}$ group and $26.3 \%$ in the DM group; between-group differences were not significant (Table 3 ).

\section{Correlations between glycated hemoglobin and re- covery ratio}

To determine whether reduced $\mathrm{HbA} 1 \mathrm{c}$ levels correlated with surgical outcomes, we analyzed the relationship between HbAlc levels and RR in all cases. There was no correlation throughout the study period (Table 4).

\section{Surgical outcomes based on the Japanese Orthopaedic Association Cervical Myelopathy Evaluation Ques- tionnaire scores}

The surgical outcomes with JOACMEQ are shown in Table 5. Postoperatively, UE and LE functions in the $\mathrm{N}$ group significantly improved. In the DM group, LE func- 
Table 2. Changes in FBG and $\mathrm{HbA1c}$ levels

\begin{tabular}{|c|c|c|c|c|}
\hline \multirow{2}{*}{ Variable } & \multirow{2}{*}{ Preoperative } & \multicolumn{3}{|c|}{ Postoperative period } \\
\hline & & 1 wk (p-value $)^{a)}$ & 4 wk (p-value $)^{\text {a) }}$ & 1 yr (p-value $)^{\mathrm{a})}$ \\
\hline \multicolumn{5}{|l|}{$N$ group $(n=42)$} \\
\hline $\mathrm{FBG}(\mathrm{mg} / \mathrm{dL})$ & $101.0 \pm 18.4$ & $93.4 \pm 15.6(0.00)$ & $97.2 \pm 20.2(0.29)$ & $103.5 \pm 23.8(0.60)$ \\
\hline HbA1c (\%) & $5.6 \pm 0.4$ & $5.6 \pm 0.4(0.68)$ & $5.5 \pm 0.4(0.07)$ & $5.6 \pm 0.3(0.19)$ \\
\hline \multicolumn{5}{|l|}{ DM group ( $n=19$ ) } \\
\hline $\mathrm{FBG}(\mathrm{mg} / \mathrm{dL})$ & $155.1 \pm 48.9$ & $115.4 \pm 21.9(0.00)$ & $114.8 \pm 29.2(0.00)$ & $149.9 \pm 50.9(0.75)$ \\
\hline $\mathrm{HbA1c}(\%)$ & $6.9 \pm 0.9$ & $6.8 \pm 0.4(0.19)$ & $6.5 \pm 0.4(0.04)$ & $6.8 \pm 0.9(0.06)$ \\
\hline
\end{tabular}

Values are presented as mean \pm standard deviation, unless otherwise stated. $\mathrm{N}$ group: a group without diabetes; DM group: a group with diabetes. FBS, fasting blood glucose; HbA1c, glycated hemoglobin; DM, diabetes mellitus.

${ }^{\text {a) }}$ Compared with perioperative value.

Table 3. Surgical outcomes as assessed on the basis of the JOA scores between the N and DM groups

\begin{tabular}{lccc} 
& \multicolumn{2}{c}{ JOA (total score) } & Recovery ratio (\%) \\
\cline { 2 - 3 } Variable & Preoperative & After 1 yr ( $p$-value) & $40.1 \pm 39.0$ \\
N group & $10.9 \pm 2.8$ & $13.5 \pm 4.8(0.01)$ & $26.3 \pm 34.4$ \\
DM group & $10.8 \pm 7.5$ & $12.9 \pm 5.0(0.01)$ & 0.41 \\
\hline$p$-value (N vs. DM group) & 0.80 & 0.35 & \\
\hline
\end{tabular}

Values are presented as mean \pm standard deviation, unless otherwise stated. N group: a group without diabetes; DM group: a group with diabetes; $p$-value: preoperative vs. after $1 \mathrm{yr}$.

JOA, Japanese Orthopaedic Association; DM, diabetes mellitus.

Table 4. Correlations between hemoglobin A1c and recovery ratio levels

\begin{tabular}{lcc} 
Variable & Correlation coefficient & $p$-value \\
Preoperative & -0.15 & 0.26 \\
At 1 wk & -0.13 & 0.30 \\
At 4 wk & -0.02 & 0.85 \\
At 1 yr & -0.02 & 0.99 \\
\hline
\end{tabular}

Pearson's correlation coefficient.

tion improved significantly, and UE function tended toward improvement $(p=0.051)$. There were no significant between-group differences for each parameter of the effective value.

\section{Characteristics of the DMG and DMB groups}

The ratio of males to females was higher in the DMG group than in the DMB group. There were no significant physical differences between the groups. Bowel and bladder disturbances were observed more frequently in the DMG group than in the DMB group (Table 6).
7. Surgical outcomes based on the Japanese Orthopaedic Association scores between the DMG and DMB groups

JOA scores were significantly improved in both groups postoperatively (DMG group, $p<0.03$; DMB group, $p<0.02$ ). The RR was $30.1 \%$ in the DMG group and $19.8 \%$ in the DMB group. The RR did not significantly differ between the two groups (Table 7).

\section{Surgical outcomes based on the Japanese Orthopaedic} Association Cervical Myelopathy Evaluation Questionnaire scores between the DMG and DMB groups

The DMG group exhibited less improvement in UE and LE surgical outcomes (Table 8).

\section{Changes in peripheral conduction time between the DMG and DMB groups}

Preoperative PCT results are shown in Table 9. The PCT of the ulnar and tibial nerves did not significantly differ 
Table 5. Surgical outcomes as assessed on the basis of the JOACMEO scores between the N and DM groups

\begin{tabular}{|c|c|c|c|c|c|}
\hline \multirow[b]{2}{*}{ Group } & \multicolumn{5}{|c|}{ JOACMEQ } \\
\hline & $\begin{array}{l}\text { Cervical } \\
\text { function }\end{array}$ & $\begin{array}{l}\text { Upper extremity } \\
\text { function }\end{array}$ & $\begin{array}{l}\text { Lower extremity } \\
\text { function }\end{array}$ & $\begin{array}{l}\text { Bowel \& } \\
\text { bladder }\end{array}$ & Quality of life \\
\hline \multicolumn{6}{|l|}{$\mathrm{N}$ group } \\
\hline No. of patients & 37 & 38 & 36 & 37 & 42 \\
\hline \multicolumn{6}{|l|}{ Score } \\
\hline Preoperative & $67.5 \pm 30.8$ & $64.6 \pm 23.3$ & $44.6 \pm 27.3$ & $66.2 \pm 18.2$ & $45.3 \pm 16.0$ \\
\hline At $1 \mathrm{yr}$ & $71.8 \pm 24.4$ & $79.3 \pm 17.7$ & $56.6 \pm 20.8$ & $70.7 \pm 22.4$ & $51.5 \pm 17.9$ \\
\hline EV & $4.3 \pm 28.8$ & $14.7 \pm 22.2$ & $12.1 \pm 23.7$ & $4.5 \pm 20.3$ & $6.2 \pm 18.1$ \\
\hline$p$-value (preoperative vs. 1 yr) & 0.36 & $<0.01$ & $<0.01$ & 0.18 & 0.31 \\
\hline \multicolumn{6}{|l|}{ DM group } \\
\hline No. of patients & 12 & 18 & 19 & 16 & 19 \\
\hline \multicolumn{6}{|l|}{ Score } \\
\hline Preoperative & $55.4 \pm 27.9$ & $70.9 \pm 17.4$ & $52.3 \pm 16.4$ & $67.5 \pm 13.9$ & $38.6 \pm 18.9$ \\
\hline At $1 \mathrm{yr}$ & $50.0 \pm 26.0$ & $82.7 \pm 18.1$ & $68.3 \pm 26.0$ & $72.1 \pm 17.0$ & $48.9 \pm 18.1$ \\
\hline EV & $6.3 \pm 37.4$ & $12.0 \pm 24.3$ & $15.9 \pm 29.6$ & $4.6 \pm 19.0$ & $10.3 \pm 16.6$ \\
\hline$p$-value (preoperative vs. 1 yr) & 0.55 & 0.05 & 0.03 & 0.35 & 0.14 \\
\hline
\end{tabular}

Values are presented as number or mean \pm standard deviation, unless otherwise stated. $\mathrm{N}$ group: a group without diabetes; DM group: a group with diabetes.

JOACMEQ, JOA Cervical Myelopathy Evaluation Questionnaire; DM, diabetes mellitus; EV, effective value.

Table 6. Characteristics and demographics of the DMG and DMB groups

\begin{tabular}{|c|c|c|c|}
\hline Characteristic & DMG group & DMB group & $p$-value \\
\hline Age (yr) & $66.4 \pm 10.3$ & $74.1 \pm 10.1$ & $0.11^{\text {a) }}$ \\
\hline Gender (male:female) & $10: 1$ & $2: 5$ & $<0.01$ \\
\hline Height (cm) & $160.1 \pm 9.1$ & $160.4 \pm 12.4$ & $0.87^{\text {a) }}$ \\
\hline Body mass index $\left(\mathrm{kg} / \mathrm{m}^{2}\right)$ & $23.3 \pm 3.3$ & $23.2 \pm 4.2$ & $0.93^{\mathrm{a})}$ \\
\hline Weight (kg) & $60.5 \pm 12.4$ & $59.4 \pm 11.2$ & $0.70^{\text {a) }}$ \\
\hline CSM:OPLL & $8: 4$ & $6: 1$ & $0.50^{\mathrm{bl}}$ \\
\hline \multicolumn{4}{|c|}{ Peripheral conduction time (ms) } \\
\hline Ulna (right) & $15.3 \pm 2.3$ & $17.4 \pm 6.2$ & $0.61^{\text {a) }}$ \\
\hline Ulna (left) & $15.5 \pm 2.7$ & $17.3 \pm 5.2$ & $0.32^{\text {a) }}$ \\
\hline Tibia (right) & $25.6 \pm 2.9$ & $27.1 \pm 3.0$ & $0.55^{\mathrm{a})}$ \\
\hline Tibia (left) & $25.6 \pm 3.1$ & $26.8 \pm 3.0$ & $0.55^{\text {a) }}$ \\
\hline JOA & $11.1 \pm 3.1$ & $10.4 \pm 1.1$ & $0.55^{\text {a) }}$ \\
\hline \multicolumn{4}{|l|}{ JOACMEO } \\
\hline Cervical & $64.6 \pm 32.2$ & $59.3 \pm 28.3$ & $0.70^{\mathrm{al}}$ \\
\hline Upper extremity & $73.5 \pm 18.6$ & $70.6 \pm 18.9$ & $0.63^{\mathrm{a})}$ \\
\hline Lower extremity & $54.8 \pm 27.8$ & $48.1 \pm 28.4$ & $0.55^{\mathrm{a})}$ \\
\hline Bowel \& bladder & $77.8 \pm 15.5$ & $61.4 \pm 12.2$ & $0.02^{\mathrm{a})}$ \\
\hline Quality of life & $42.2 \pm 19.7$ & $32.4 \pm 17.1$ & 0.18 \\
\hline
\end{tabular}

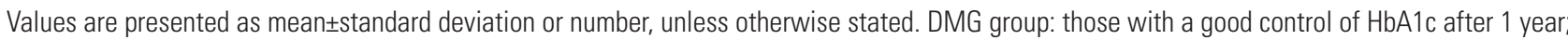
DMB group: those with $\mathrm{HbA1c}$ deterioration after 1 year.

DM, diabetes mellitus; CSM, cervical spondylotic myelopathy; OPLL, ossification of the posterior longitudinal ligament; JOA, Japanese Orthopaedic Association; JOACMEQ, JOA Cervical Myelopathy Evaluation Questionnaire; HbA1c, glycated hemoglobin.

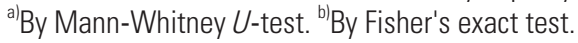


Table 7. Surgical outcomes between the DMG and DMB groups as assessed on the basis of the JOACMEO scores

\begin{tabular}{lccc} 
& \multicolumn{2}{c}{ JOA (total score) } & Recovery ratio (\%) \\
\cline { 2 - 3 } Variable & Preoperative & At 1 yr ( $p$-value) & $30.1 \pm 48.0$ \\
DMG group & $11.1 \pm 3.1$ & $13.6 \pm 2.1(0.03)$ & $19.8 \pm 15.9$ \\
DMB group & $10.4 \pm 2.5$ & $11.7 \pm 2.0(0.02)$ & 0.44 \\
\hline$p$-value (DMG vs. DMB) & 0.55 & 0.06 & \\
\hline
\end{tabular}

Values are presented as mean \pm standard deviation or number, unless otherwise stated. DMG group: those with a good control of HbA1c after 1 year; DMB group: those with $\mathrm{HbA} 1 \mathrm{c}$ deterioration after 1 year.

DM, diabetes mellitus; JOACMEQ, JOA Cervical Myelopathy Evaluation Questionnaire; JOA, Japanese Orthopaedic Association; HbA1c, glycated hemoglobin.

Table 8. Surgical outcomes between the DMG and DMB groups as assessed on the basis of the JOA scores

\begin{tabular}{l} 
Variable \\
\cline { 2 - 5 }
\end{tabular}

Values are presented as number or mean \pm standard deviation, unless otherwise stated. DMG group: those with a good control of HbA1c after 1 year; DMB group: those with $\mathrm{HbA1c}$ deterioration after 1 year.

DM, diabetes mellitus; JOA, Japanese Orthopaedic Association; JOACMEO, JOA Cervical Myelopathy Evaluation Questionnaire; EV, effective value; HbA1c, glycated hemoglobin.

between the DMG and DMB groups.

\section{Discussion}

We evaluated surgical outcomes associated with CSM. Surgical outcomes based on JOA scores were not significantly different between the $\mathrm{N}$ and DM groups. Furthermore, there were no significant differences relative to DM control. In fact, with respect to the RR with JOA, there were no significant differences between the $\mathrm{N}$ and $\mathrm{DM}$ groups and between the DMG and DMB groups with re- spect to the presence of DM. Poor glycemic control affected CSM surgical outcomes as indicated by the JOACMEQ evaluation. We conclude that poor DM control impaired surgical outcomes in patients with CSM. Previous studies have reported that preoperative $\mathrm{HbAlc}$ levels affected recovery after CSM surgery [4,5]. DM is a risk factor for poor lumbar and cervical spinal surgery outcomes [12-15]. However, previous studies have focused only on the presence of DM, not on postoperative DM control.

DM affects outcomes of all types of spinal surgeries, yet most studies do not include postoperative DM control. 
Table 9. Changes in PCT between the DMG and DMB groups

\begin{tabular}{lcccc} 
& \multicolumn{3}{c}{ PCT (ms) } \\
\cline { 2 - 5 } Variable & Ulna (right) & Ulna (left) & Tibia (right) & Tibia (left) \\
\hline DMG group & & & & \\
\hline Preoperative & $18.3 \pm 7.8$ & $18.2 \pm 6.4$ & $26.7 \pm 3.1$ & $25.6 \pm 3.1$ \\
\hline At 1 yr & $16.0 \pm 3.0$ & $16.7 \pm 3.2$ & 0.12 & $26.5 \pm 2.7$ \\
\hline$p$-value (preoperative vs. 1 yr) & 0.14 & 0.18 & 0.18 \\
\hline DMB group & & & & $27.7 \pm 2.8$ \\
\hline Preoperative & $15.9 \pm 0.8$ & $15.6 \pm 1.5$ & $27.5 \pm 3.1$ & $27.4 \pm 3.6$ \\
\hline At 1 yr & $16.0 \pm 1.1$ & $15.8 \pm 1.5$ & 0.61 & $27.5 \pm 3.2$ \\
\hline -value (preoperative vs. 1 yr) & 0.78 & 0.47 & 0.86 \\
\hline
\end{tabular}

Values are presented as mean \pm standard deviation or number, unless otherwise stated. DMG group: those with a good control of $\mathrm{HbA1c}$ after 1 year; DMB group: those with $\mathrm{HbA} 1 \mathrm{c}$ deterioration after 1 year.

$\mathrm{PCT}$, peripheral conduction time; $\mathrm{DM}$, diabetes mellitus; $\mathrm{HbA1C}$, glycated hemoglobin.

The between-group differences in surgical outcomes in our study and in previous studies might be explained by conditional differences in patients with DM.

Diabetic neuropathy is one of the main factors in the diagnosis of patients with myelopathy. Nakanishi et al. [7] reported that the PCT of UE and LE were affected in patients with DM and CSM. This same study mentioned the possibility of DM causing peripheral nerve dysfunction, thereby affecting surgical outcomes. Generally, initial changes associated with diabetic neuropathy include extension of tibial F-wave latency $[16,17]$. In this study, no cases exhibited clear extension of F-wave latency. There were no significant differences between preoperative and postoperative PCTs in the DM group.

Patients with poor DM control often experience poorer recovery postoperatively than patients with good DM control. However, our results showed that peripheral disorders associated with DM did not directly affect surgical outcomes.

We could not identify the mechanism(s) by which DM was associated with CSM; however, we consider two theories relevant. The first of these involves DM-linked microangiopathy. Microangiopathy interferes with nutrient diffusion through the vertebral endplate, potentially leading to disk degeneration [12]. It is possible that DM angiopathy, therefore, interferes with nutrient delivery to other organs, including the spinal cord. Several studies mention possible spinal cord ischemia in patients with DM [18-20]. Mawad et al. [21] evaluated 24 patients who developed signs and symptoms of spinal cord ischemia or infarction following thoracoabdominal aortic aneurysm surgery using MRI. They determined that DM was a predisposing risk factor for the development of postoperative spinal cord ischemia [21]. DM angiopathy might, therefore, affect surgical outcomes.

Our second theory involves DM myelopathy. Following a post-mortem study, Reske-Nielsen and Lundbaek [22] have reported that patients with type 1 DM exhibited cranial nerve demyelination. There are other reports that describe a possible association between DM and central cord demyelination, axonal loss, and gliosis $[23,24]$.

Selvarajah et al. [25] have investigated the relationship between spinal cord atrophy and neurophysiological assessments among patients with DM by measuring the diameter of the spinal cord with MRI. Spinal cord atrophy is observed in patients with DM regardless of the presence or absence of diabetic peripheral neuropathies [25]. Although DM-related cervical cord atrophy is a potential factor, it is difficult to preoperatively measure the cord diameter using MRI in patients with severe stenosis. In any case, poor control of DM appears to be a risk factor for microangiopathy and nervous system injury [26-28].

The 6.5-year Diabetes Control and Complication Trial in the United States divided patients with DM into two groups. The first group included patients receiving 'typical' DM therapy. The average HbAlc level in this group during the study was approximately $9.0 \%$. The other group of patients received strictly controlled DM therapy. The average $\mathrm{HbAlc}$ level in this group during the study was approximately $7.0 \%$. The prevalence of DM neuropathy 
was $13 \%$ among the patients receiving typical DM therapy and $5.0 \%$ among those receiving a stricter DM therapy at the end of this trial. DM control, therefore, appears to be important for preventing complications associated with DM, including neuropathy and angiopathy [29,30]. In this study, all the patients were under strict blood glucose control before surgery; after that, the patients who did not experience poorer blood glucose control exhibited good surgical outcomes. We believe that we can achieve good surgical outcomes in patients with CSM by enacting strict glycemic controls both preoperatively and postoperatively.

This study has several limitations. First, many patients were excluded because of a lack of data, particularly regarding HbA1c levels or PCT values at the 1-year followup. Second, we investigated only FBG and HbA1c levels during the perioperative period and at 1 year postoperatively. We did not record glycemic control between these time points. Despite these limitations, we believe that strict control of DM is necessary for achieving good longterm outcomes.

\section{Conclusions}

Postoperative improvement in CSM varies in association with control of DM symptoms during the preoperative and postoperative periods. We believe that poor glycemic control might prevent postoperative functional recovery of CSM.

\section{Conflict of Interest}

No potential conflict of interest relevant to this article was reported.

\section{References}

1. Lees F, Turner JW. Natural history and prognosis of cervical spondylosis. Br Med J 1963;2:1607-10.

2. Hayashi H, Okada K, Hashimoto J, Tada K, Ueno R. Cervical spondylotic myelopathy in the aged patient: a radiographic evaluation of the aging changes in the cervical spine and etiologic factors of myelopathy. Spine (Phila Pa 1976) 1988;13:618-25.

3. Machino M, Yukawa Y, Ito K, et al. Impact of diabetes on the outcomes of cervical laminoplasty: a prospective cohort study of more than 500 patients with cervical spondylotic myelopathy. Spine (Phila
Pa 1976) 2014;39:220-7.

4. Kawaguchi Y, Matsui H, Ishihara H, Gejo R, Yasuda T. Surgical outcome of cervical expansive laminoplasty in patients with diabetes mellitus. Spine (Phila $\mathrm{Pa}$ 1976) 2000;25:551-5.

5. Dokai T, Nagashima H, Nanjo Y, Tanida A, Teshima R. Surgical outcomes and prognostic factors of cervical spondylotic myelopathy in diabetic patients. Arch Orthop Trauma Surg 2012;132:577-82.

6. Kim HJ, Moon SH, Kim HS, et al. Diabetes and smoking as prognostic factors after cervical laminoplasty. J Bone Joint Surg Br 2008;90:1468-72.

7. Nakanishi K, Tanaka N, Kamei N, et al. Electrophysiological assessments of the motor pathway in diabetic patients with compressive cervical myelopathy. J Neurosurg Spine 2015;23:707-14.

8. Yonenobu K, Abumi K, Nagata K, Taketomi E, Ueyama K. Interobserver and intraobserver reliability of the japanese orthopaedic association scoring system for evaluation of cervical compression myelopathy. Spine (Phila Pa 1976) 2001;26:1890-4.

9. Fukui M, Chiba K, Kawakami M, et al. JOA Back Pain Evaluation Questionnaire (JOABPEQ)/JOA Cervical Myelopathy Evaluation Questionnaire (JOACMEQ): the report on the development of revised versions. April 16, 2007. The Subcommittee of the Clinical Outcome Committee of the Japanese Orthopaedic Association on Low Back Pain and Cervical Myelopathy Evaluation. J Orthop Sci 2009;14:34865.

10. Hirabayashi K, Miyakawa J, Satomi K, Maruyama T, Wakano K. Operative results and postoperative progression of ossification among patients with ossification of cervical posterior longitudinal ligament. Spine (Phila Pa 1976) 1981;6:354-64.

11. Kimura J. F-wave velocity in the central segment of the median and ulnar nerves: a study in normal subjects and in patients with Charcot-Marie-Tooth disease. Neurology 1974;24:539-46.

12. Anekstein Y, Smorgick Y, Lotan R, et al. Diabetes mellitus as a risk factor for the development of lumbar spinal stenosis. Isr Med Assoc J 2010;12:16-20.

13. Kim KT, Cho DC, Sung JK, Kim CH, Kang H, Kim $\mathrm{DH}$. Changes in $\mathrm{HbA}(1 \mathrm{c})$ levels and body mass index after successful decompression surgery in patients with type 2 diabetes mellitus and lumbar spinal stenosis: results of a 2 -year follow-up study. Spine J 
2017;17:203-10.

14. Browne JA, Cook C, Pietrobon R, Bethel MA, Richardson WJ. Diabetes and early postoperative outcomes following lumbar fusion. Spine (Phila Pa 1976) 2007;32:2214-9.

15. Arinzon Z, Adunsky A, Fidelman Z, Gepstein R. Outcomes of decompression surgery for lumbar spinal stenosis in elderly diabetic patients. Eur Spine J 2004;13:32-7.

16. Kohara N, Kimura J, Kaji R, et al. F-wave latency serves as the most reproducible measure in nerve conduction studies of diabetic polyneuropathy: multicentre analysis in healthy subjects and patients with diabetic polyneuropathy. Diabetologia 2000;43:91521.

17. Pan H, Jian F, Lin J, et al. F-wave latencies in patients with diabetes mellitus. Muscle Nerve 2014;49:804-8.

18. Tanida A, Kamimura A, Tanishima S, Mihara T, Takeda C, Nagashima H. Spinal cord infarction at the level of ossification of the posterior longitudinal ligament. Spinal Cord Ser Cases 2016;2:16032.

19. Rigney L, Cappelen-Smith C, Sebire D, Beran RG, Cordato D. Nontraumatic spinal cord ischaemic syndrome. J Clin Neurosci 2015;22:1544-9.

20. Millichap JJ, Sy BT, Leacock RO. Spinal cord infarction with multiple etiologic factors. J Gen Intern Med 2007;22:151-4.

21. Mawad ME, Rivera V, Crawford S, Ramirez A, Breitbach W. Spinal cord ischemia after resection of thoracoabdominal aortic aneurysms: MR findings in 24 patients. AJR Am J Roentgenol 1990;155:1303-7.

22. Reske-Nielsen E, Lundbaek K. Pathological changes in the central and peripheral nervous system of young long-term diabetics: II. the spinal cord and peripheral nerves. Diabetologia 1968;4:34-43.

23. Selvarajah D, Tesfaye S. Central nervous system involvement in diabetes mellitus. Curr Diab Rep 2006;6:431-8.

24. Slager UT. Diabetic myelopathy. Arch Pathol Lab Med 1978;102:467-9.

25. Selvarajah D, Wilkinson ID, Emery CJ, et al. Early involvement of the spinal cord in diabetic peripheral neuropathy. Diabetes Care 2006;29:2664-9.

26. Tesfaye S, Chaturvedi N, Eaton SE, et al. Vascular risk factors and diabetic neuropathy. N Engl J Med 2005;352:341-50.

27. Adler AI, Boyko EJ, Ahroni JH, Stensel V, Forsberg RC, Smith DG. Risk factors for diabetic peripheral sensory neuropathy: results of the Seattle Prospective Diabetic Foot Study. Diabetes Care 1997;20:1162-7.

28. Partanen J, Niskanen L, Lehtinen J, Mervaala E, Siitonen O, Uusitupa M. Natural history of peripheral neuropathy in patients with non-insulin-dependent diabetes mellitus. N Engl J Med 1995;333:89-94.

29. Diabetes Control and Complications Trial Research Group, Nathan DM, Genuth S, et al. The effect of intensive treatment of diabetes on the development and progression of long-term complications in insulin-dependent diabetes mellitus. N Engl J Med 1993;329:977-86.

30. The Diabetes Control and Complications Trial Research Group. The effect of intensive diabetes therapy on the development and progression of neuropathy. Ann Intern Med 1995;122:561-8. 